\title{
Ecological niche modelling of the wattled crane (Bugeranus carunculatus) suggest range expansion and contraction during the Pleistocene
}

Daniel Augusta Zacarias

\begin{abstract}
Universidade Eduardo Mondlane, Escola Superior de Hotelaria e Turismo de
Inhambane. Cidade de Inhambane, Bairro Chalambe-2, Av. Samora Machel, Caixa

Postal 75
\end{abstract}

daniel.zacarias15@gmail.com 


\title{
Ecological niche modelling of the wattled crane (Bugeranus carunculatus) suggest range expansion and contraction during the Pleistocene
}

\begin{abstract}
This paper attempts to understand the potential effects of historical climate changes on the distribution of the wattled crane (Bugeranus carunculatus). The potential distribution in past and present climatic scenarios is investigated through ensemble distribution modelling of 232 independent and sparsely distributed occurrence records. Potential effects of climate change were evaluated by means on niche overlap and niche gains and losses across time scales. Massive range expansion was observed from the Last Interglacial (LIG) era to the Last Glacial Maximum (LGM), with loss of suitability in most areas of western Africa and an increase in suitability across southern and eastern Africa. From the LGM, climate suitability tended to establish in southern and eastern Africa with slight disjunction in the midHolocene, a trend that was maintained through current distribution. Results indicate the presence of southern and northern refugia, with massive range expansion in central populations. These results support the idea that the current disjunct distribution of the wattled crane is driven by climate oscillations during the Pleistocene that generated range expansion and retraction of the species and also support the hypothesis that the current occurrence of the species is driven by other factors such as food and habitat availability.
\end{abstract}

Keywords: climate change, range shifts, disjunct distribution, paleodistribution modelling, birds, range expansion-contraction theory. 


\section{Introduction}

Disjunct distribution of species has always intrigued biogeography (Deng et al., 2015; Beatty and Provan, 2013). However, consensus do exist that species distribution is determined by the interaction between biotic, abiotic and historical factors (Peterson et al., 2011; Brown et al. 1996). While this interaction is commonly understood when attempting to explain the distribution of continuous species, the situation gets rather complex when attempting to explain complex disjunct distributions. Several approaches and studies have been developed to understand why single species are located in different areas, with two traditional hypotheses having received extensive consideration: vicariance and dispersal (González et al., 2014; Lozano-Jaramillo et al., 2014).

On one side, the vicariance hypothesis, assumes that current disjunct distributions are relicts of former continuous distributions (Karanth, 2003), caused by range contractions due to changes in climatic conditions that might have affected habitat suitability (Cox and Moore, 2005). As such, species disjunct distribution is a result of the fragmentation of ancestral wide distribution caused by the appearance of any barrier. On the other side, the dispersal hypothesis assumes that disjunct distributions are a result of long-distance dispersal to suitable habitats (Cox and Moore, 2005) through a pre-existing dispersal barrier (Kropf et al., 2006). These patterns are extensively studied through species paleodistribution modelling (Wethey et al., 2016; Pena et al., 2014), phylogenetic analysis of divergence (Deng et al., 2015; Hawlitschek et al., 2015) or a combination of both (Thesing et al., 2016; Vitorino et al., 2016; Lozano-Jaramilo et al., 2014). These hypotheses, though, are not mutually exclusive and consensus is that long-term maintenance of disjunct 
distributions is dependent on the environmental unsuitability of surrounding areas and/or adaptation to different environmental conditions of geographically distinct areas (Lozano-Jaramilo et al., 2014; Gatson, 2003).

In times of increasing biodiversity loss, disjunct species distribution can be a great challenge to species long-term persistence (Byrne et al., 2016; Rubinoff et al., 2015; Marchant et al., 2015), mainly because land degradation and fragmentation can heavily affect smaller and discontinuous ranges (Sandel et al., 2011) accelerating species extinction (Sobral-Souza et al., 2015; Harris and Pimm, 2008). In addition, disjunct distributions challenge biodiversity conservation, as conservation needs to understand and choose whether to protect the species as a whole or as special management units (Measey and Tolley, 2011). This is particularly difficult when historical information is lacking and conservation actions need to be urgently considered (Pena et al., 2014; Measey and Tolley, 2011).

One of the key features of cranes worldwide is the dominance of disjunct distributions. Of the 15 extant crane species (Duan and Fuerst, 2001; Meine and Archibald, 1996), only the sandhill crane, Grus canadensis, appears to have a single continuous distribution. The wattled crane, Bugeranus carunculatus, presents an intriguing disjunct distribution across southern and eastern Africa consisting of three major populations, namely: the south-central population along the Okavango delta and the Kafue flats, the South African population and the Ethiopian populations (Bento et al., 2007; Jones et al., 2006; Meine and Archibald, 1996). Like the majority of crane species, the wattled crane is threatened with extinction, being classified as vulnerable (VU; A2acde+3cde; $\mathrm{C} 1+2 \mathrm{a}$ ) by the International Union for Conservation of 
Nature (IUCN) and enlisted at the Appendix II of the Convention on International Trade in Endangered Species of Wild Fauna and Flora (CITES) and the Convention on Migratory Species (CMS).

Little is known about the reasons behind the origin of the current disjunction of $B$. carunculatus distribution, with existing knowledge considering that south African and Ethiopian populations are relicts of a past continuous distribution (Beilfuss et al., 2003). However, considering the climatic oscillations during the Pleistocene period, it is plausible to assume that the sequence of relatively warmer and wetter (Last Interglacial - LIG) and cooler and drier (Last Glacial Maximum - LGM) climate conditions (Gavashelishvili and Tarkhnishvili, 2016) might have driven changes in the geographic distribution of species, associated to the contraction of lowland forest and savannah and the ability of the species to track suitable climatic conditions.

In addition, considering the relative dependence of the species in relation to lowland floodplain habitats and the presence of Eleocharis spp., it is also plausible to postulate that the disjunct distribution of $B$. carunculatus might also be a result of its climate specialist behaviour that has maintained its distribution with respect to climate and vegetation types. This paper explores these assumptions, based on distribution modelling of the species through the Afrotropical realm in 4 consecutive climatic timescales: the Last Interglacial (LIG), the Last Glacial Maximum (LGM), the Mid-Holocene (Mid-H) and contemporary climate.

\section{Material and methods}

\subsection{Species occurrence records}


Occurrence records were retrieved from the Global Biodiversity Information Facility (GBIF; GBIF.org), encompassing historical $(n=47)$ and contemporary records $(n=$ 6224). After checking for data inconsistencies, duplicates and errors, 3625 records were retained for further analysis (Table S1). These records were then spatially filtered (Boria et al., 2013) considering a species home range of $16 \mathrm{~km}^{2}$ (McCann and Benn, 2006), resulting in 232 independent records (Figure 1) that were then used to model the potential climatic distribution of the species. Spatial filtering was done using the SDMtoolbox (Brown et al., 2017; Brown, 2014;) in ArcGIS 10.5.

\subsection{Bioclimatic variables}

Current bioclimatic variables associated to annual mean temperature (bio1), temperature seasonality (bio4), maximum temperature of the warmest period (bio5), annual precipitation (bio12), precipitation seasonality (bio15) and precipitation of the driest quarter (bio17) were downloaded from the World Climate Database (http://www.worldclim.org; Hijmans et al., 2005) at a spatial resolution of $2.5 \mathrm{~min}$. These variables were chosen because they (i) have been extensively applied in studies of birds' response to climate change in several environments (Ribeiro et al., 2016; Barbet-Massin and Jetz 2015; Reside et al., 2012) and (ii) fulfil some of the most important biological requirements for birds (Bateman et al., 2016; Reside et al., 2012). For past climatic conditions, the same bioclimatic variables were used, at the same resolution. As for the Mid-Holocene (Mid-H; 6kya) and Last Glacial Maximum (LGM; 22kya), climate variables spanned three global ocean circulation models (AOGCMs), namely: CCSM4, MIROC-ESM and MPI-ESM-P. For the Last InterGlacial (LIG; 120kya - 140kya), data were downloaded at a resolution of 30 arc- 
seconds and rescaled to the same resolution as other variables ( $2.5 \mathrm{~min})$ using the rescale toolbox of the SDMtoolbox (Brown et al. 2017; Brown 2014) in ArcGIS.

\subsection{Species distribution modelling}

Potential climatic distribution of the species was predicted using biomod2 (Thuiller et al., 2016) an ensemble platform for species distribution modelling. Climatic suitability was first predicted for current climate scenario and then projected into past scenarios, using nine algorithms (Table S2). For each model, occurrence records were randomly partitioned into training (75\%) and test (25\%) datasets, with 5 replications. The True Skills Statistics (TSS) and Area Under the Curve (AUC) evaluated models predictive capability. For each climate scenario (except for the LIG, were only dataset was available) an ensemble of all nine algorithms was calculated (Tinker et al., 2015; Loyola et al., 2013), resulting in consensus maps of potential climatic distribution. As for the LGM and Mid-H, maps of potential climate suitability across AOGCMs were averaged to generate a map of potential suitability for each climate scenario per climatic era (Hovick et al., 2015; Loyola et al., 2013).

\subsection{Potential distribution, range shifts and refugia}

Maps resulting from species distribution modelling indicate the climatic suitability of the species across a continuous gradient ranging from 0 to 1 , were 0.5 indicates random distribution and 1 optimum distribution. To understand areas with higher probability of species presence, all maps were converted into a binary distribution with values equal or lower that 0.5 indicating areas with no presence of the species and otherwise indicating presence of the species. The resulting binary maps were used to assess potential range shifts across timescales and gains and losses of 
climatic suitability. For every pair of climatic timescales the earlier prediction was subtracted by the older prediction to generate range variations of -1 (range contraction) and 1 (range expansion).

For each timescale, the number of occupied grids was counted to calculate the size of habitat contraction, expansion and stability. All maps were summed to calculate potential refugia areas, i.e. areas that were potentially suitable for the species since the Last Interglacial climatic scenario (Ban et al. 2016; Keppel et al. 2011). Niche similarity (or dissimilarity) across timescales was calculated based on the Schoener's $D$ (Schoener, 1968) and Warren's I statistics (Warren et al., 2009) using the nicheOverlap function of the dismo package (Hijmans et al., 2016) in R (R Core Team, 2017). These statistics compute the degree of ecological overlap between two datasets at a scale of 0 to 1 , with values near 0 associated to niche dissimilarity (no overlap) between two datasets and values near 1 associated to high niche similarity (niche overlap) (Broennimann et al., 2012).

\section{Results}

Models evaluation indicated that, overall, all models had predictive capacity better than random (Table S2). The lower TSS and AUC values were associated to the Surface Range Envelop (0.710 \pm 0.054 and $0.855 \pm 0.027$, respectively) and the highest was associated to the Random Forest algorithm (0.902 \pm 0.023 and $0.980 \pm$ 0.006 , respectively). The potential distribution of the species through time is displayed in Figure 2, with the predicted current distribution largely matching the current distribution as estimated by the IUCN extent of occurrence, suggesting equilibrium with current climate. As for the past, the distribution of the wattled crane 
demonstrated distribution during the LGM and progressive shrinkage in the following scenarios, suggesting climatic instability during the Pleistocene (Figure 2; Figure S1).

A high dissimilarity was found between suitable climatic areas between the LIG and LGM (Schoener's D = 0.255, Warren's I = 0.398, Table 1 ) and similarity between the suitable areas in Mid-H and current climatic scenarios (Schoener's D $=0.860$, Warren's I = 0.895), suggesting that there has been an improvement of the climatic conditions for the species from the LGM to the mid-Holocene and relative stability in the last 6000 years. These results suggest a dynamic distribution of climatically suitable areas for B. carunculatus, highlighting South African and Ethiopian populations as possible refugia (Figure 3).

\section{Discussion}

Results herein reported, suggest that at any period in the past the wattled crane had scattered distribution across the Afrotropics, but benefited from an improvement of bioclimatic conditions during the transition from the LIG to the LGM that increased suitability in southern, the area that is currently occupied by the core population of the species. The modelling process accurately matched the current distribution and highlighted the presence of two refugia in eastern and southern Africa, thus providing evidence for the glacial refugia hypothesis (Brito, 2005).

The increase of suitability in southern Africa, though, is a complex process with complex understanding, but can be associated to the biogeography of the presentday central Africa and the dynamics of the Congo-Zambezi system that influenced the distribution and evolution of tropical Africa's biota (Schultheiß et al., 2014) due to 
the formation of the East African Rift System (EARS). This complex system affected the distribution of tropical flora and fauna, but had a decisive role in creating, disrupting, redirecting and connecting freshwater systems (Schultheiß et al., 2014; Roberts et al., 2012) essential to the survival of the wattled crane. This connectivity between the Congo and the Zambezi river system can explain the persistence of wattled cranes in southern Africa, due to the prevalence of extensive shallow floodplains that provide sufficient habitat and resources for the species.

Results, herein, contradict the former assumption that South African and Ethiopian populations are relicts of a former broader continuous distribution of wattled cranes in Africa (Beilfuss et al. 2003), but rather establish that these populations might be climatic refugia of the species that have maintained effective numbers through time. In addition, the current distribution of the species appears to be also a result of low dispersal ability of the species (Jones et al. 2006). B. carunculatus current distributions appear to follow lowlands surrounding the major afromontane ecosystems in Africa, that might imply that the rise of the Rift Valley ecoregion might have been responsible in separating the Ethiopian population from the south-central population. However, reasons behind possible separation between south-central population and the South African population remain unclear, although the limited dispersal hypothesis might be considered the starting point.

Nevertheless, results herein, support the hypothesis that wattled cranes has once in time established across western Africa (Birdlife International, 2018). As illustrated in Figure 2, there have been areas with scattered climatic suitability through time that could have possibly harboured cranes. Due to climate oscillations during the 
Quaternary, associated to the deepening of major swell in Western Africa and consequently disappearance of shallow floodplains (Miller and Gosling, 2014). In addition, the distribution of the wattled cranes can also be attributed to main climatic events during early years of the quaternary that created conditions for the emergence of barriers to the dispersal of the species (Burke and Wilkinson, 2016; Mark and Osmaston, 2008) mainly by the lack of important food resources (Jones et al. 2006). Adding to this, it has been emphasized that the climatic regime associated to the last glaciations during the LGM have created conditions for the prevalence of swells and shallow floodplains nearby the afromontane complexes (Burke and Wilkinson, 2016; Osmaston and Harrison, 2005) that might have created sufficient conditions for the persistence of the species due to its high adaptability to new environments.

Although this study does not integrate phylogenetic analysis, its results when associated to the biology of the species provide sufficient evidence to support the hypothesis that the current distribution of $B$. carunculatus is a result of complex range-shifts during the Quaternary that improved suitable conditions for the core population in southern Africa and enabled the persistence of two refugia for the south African and Ethiopian populations. Nevertheless, the incorporation of phylogenetic studies might shed new lights into this complex debate and provide additional insights into species long-term persistence and guide management practices. Previous attempts to estimate genetic relatedness between south-central and South African populations has indicated that South African populations have comparable levels of genetic variation as to the south-central, despite lack of gene flow between them as a result of lack of matrilineal gene flow across the region (Jones et al. 2006). 
This study is the first experience to attempt to understand the origin of the current disjunct distribution of the wattled crane. Results indicated that climate changes during the Quaternary drove the current distribution of the species by improving environmental conditions in southern Africa and isolating two refugia, one in South Africa and the other in Ethiopia. As such, results support the hypothesis that the current distribution of $B$. carunculatus is a vicariance-based process associated to the great adaptability potential of the species to survive in areas that are currently not suitable but, still, provide enough food resources such as the Zambezi delta in central Mozambique. Further work on the intra and interspecific genetic variation and phylogenetic analysis of extant and populations is recommended to further uncover the colonization history and to identify whether the predicted climatic refugia are, simultaneously, genetic refugia and to validate the hypothesis of no dispersal among B. carunculatus populations.

Nevertheless, the present distribution indicate that relatively high proximity to heavy occupied settlements that can hinder future prospects of species survival, especially when considering the increasing demand for water supply that has resulted in extensive drainage of water systems. Considering that this species is highly sensitive to human disturbance (Morrison and Bothma, 1998), successful conservation is a challenging process that will require balancing surrounding land-uses and reduce disturbance of the species.

\section{Acknowledgements}

I wish to thank the GBIF team and contributors for making their data freely available. Software and package developers are also acknowledged. This paper benefited from 
earlier discussion with Leticia Braga. This research did not receive any specific grant from funding agencies in the public, commercial or not-for-profit sectors.

\section{References}

Ban, S.S.; Alidina, H.M.; Okey, T.A.; Gregg, R.M.; Ban, N.C. (2016). Identifying potential marine climate change refugia: A case study in Canada's Pacific marine ecosystems. Global Ecology and Conservation 8: 41-54.

Barbet-Massin, M.; Jetz, W. (2015). The effect of range changes on the functional turnover, structure and diversity of bird assemblages under future climate scenarios. Global Change Biology 21(8): 2917-2928.

Bateman, B.L.; Pidgeon, A.M.; Radeloff, V.C.; Vanderwal, J.; Thogmartin, W.E.; Vavrus, S.J.; Heglund, P.J. (2016). The pace of past climate change vs. potential bird distributions and land use in the United States. Global Change Biology 22(3): 1130-1144.

Beatty, G.E.; Provan, J. (2013). Post-glacial dispersal, rather than in situ glacial survival, best explains the disjunct distribution of the Lusitanian plant species Daboecia cantabrica (Ericaceae). Journal of Biogeography 40(2): 335-344.

Beilfuss, R.; Bento, C.; Hancock, P.; Kamweneshe, B.; McCann, K.; Morrison, K.; Rodwell, L. 2003. Water, wetlands, and wattled cranes: a regional monitoring and conservation program for Southern Africa. International Conference on Environmental Monitoring of Tropical and Subtropical Wetlands. Botswana: Okavango Research Center, Maun.

Bento, C. M.; Beilfuss, R. D.; Hockey, P. A. R. (2007). Distribution, structure and simulation modelling of the Wattled Crane population in the Marromeu Complex of the Zambezi Delta, Mozambique. Ostrich 78(2): 185-193. 
BirdLife International (2018) Species factsheet: Bugeranus carunculatus.

Downloaded from http://www.birdlife.org on 08/01/2018.

Boria, R.A.; Olson, L.E.; Goodman, S.M.; Anderson, R. (2014). Spatial filtering to reduce sampling bias can improve the performance of ecological niche models. Ecological Modelling 275: 73-77.

Brito, P. (2005). The influence of Pleistocene glacial refugia on tawny owl genetic diversity and phylogeography in western Europe. Molecular Ecology 14: 30773094.

Broennimann, O., Fitzpatrick, M.C., Pearman, P.B., Petitpierre, B., Pellissier, L., Yoccoz, N.G., Thuiller, W., Fortin, M.-J., Randin, C., Zimmermann, N.E., Graham, C.H., Guisan, A., (2012). Measuring ecological niche overlap from occurrence and spatial environmental data. Global Ecology and Biogeography 21: 481-497. Doi: 10.1111/j.1466-8238.2011.00698.x.

Brown, J.H.; Stevens, G.C.; Kaufman, D.M. (1996). The geographic range: size, shape, boundaries, and internal structure. Annual Review of Ecological Systems 27: 597-623. Doi: https://doi.org/10.1146/annurev.ecolsys.27.1.597.

Brown, J.L. (2014). SDMtoolbox: a python-based GIS toolkit for landscape genetic, biogeographic, and species distribution model analyses. Methods in Ecology and Evolution 5(7): 694-700. DOI: 10.1111/2041-210X.12200.

Brown, J.L.; Bennett, J.R.; French, C.M. (2017). SDMtoolbox 2.0: the next generation Python-based GIS toolkit for landscape genetic, biogeographic and species distribution model analyses. PeerJ 5:e4095; DOI 10.7717/peerj.4095.

Burke, K; Wilkinson, M.J. (2016). Landscape evolution in Africa during the Cenozoic and Quaternary - the legacy and limitations of Lester C. King. Canadian Journal of Earth Sciences 53: 1089-1102. Doi: dx.doi.org/10.1139/cjes-2016-0099. 
Byrne, M.; Coates, D.J.; Macdonald, B.M.; Hankinson, M.; McArthur, S.M.; Leeuwen, S. (2016). High nuclear genetic differentiation, but low chloroplast diversity in a rare species, Aluta quadrata (Myrtaceae), with a disjunct distribution in the Pilbara, Western Australia. Australian Journal of Botany 64(8): 687-695. Doi: https://doi.org/10.1071/BT16128.

Cox , C.B.; Moore, P.D. (2005). Biogeography: an ecological and evolutionary approach. Oxford: Blackwell Publishing.

Deng, T.; Nie, Z-L.; Drew, B.T.; Volis, S.; Kim, C.; Xiang, C-L.; Zhang, J.W.; Wang, Y-H.; Sun, H. (2015). Does the arcto-tertiary biogeographic hypothesis explain the disjunct distribution of northern hemisphere herbaceous plants? The case of Meehania (Lamiaceae). PLoS ONE 10(2): e0117171. Doi:

10.1371/journal.pone.0117171.

Duan, W.; Fuerst, P.A. (2001). Isolation of a sex-linked DNA sequence in cranes. Journal of Heredity 92(5): 392-397. Doi: https://doi.org/10.1093/jhered/92.5.392.

Gatson, J.K. (2003). The structure and dynamics of geographic ranges. Oxford, UK: Oxford University Press.

Gavashelishvili A., Tarkhnishvili D. (2016). Biomes and human distribution during the last ice age. Global Ecology and Biogeography 25:563-574.

González, F.; Wagner, S.T.; Salomo, K.; Symmank, L.; Samain, M-S.; Isnard, S.; Rowe, N.P.; Neinhuis, C.; Wanke, S. (2014). Present trans-Pacific disjunct distribution of Aristolochia subgenus Isotrema (Aristolochiaceae) was shaped by dispersal, vicariance and extinction. Journal of Biogeography 41, 380-391. Harris, G.; Pimm, S.T. (2008). Range size and extinction risk in forest birds. Conservation Biology 22(1): 163-171. 
Hawlitschek, O.; Scherz, M.D.; Straube, N.; Glaw, F. (2015). Resurrection of the Comoran fish scale gecko Geckolepis humbloti Vaillant, 1887 reveals a disjunct distribution caused by natural overseas dispersal. Organisms, Diversity and Evolution. Doi: 10.1007/s13127-015-0255-1.

Hijmans, R.J.; Phillips, S.; leathwick, J.; Elith, J. (2017). dismo: species distribution modelling. R package version 1.1-4. https://CRAN.Rproject.org/package=dismo.

Hijmans, R. J.; Cameron, S. E.; Parra, J. L.; Jones, P. G.; \& Jarvis, A. (2005). Very high resolution interpolated climate surfaces for global land areas. International Journal of Climatology 25: 1965-1978.

Hovick, T.J.; Dahlgren, D.K.; Papes, M.; Elmore, R.D.; Pitman, J.C. (2015). Predicting greater prairie-chicken Lek site suitability to inform conservation actions. PLoS ONE 10(8): e0137021. Doi: https://doi.org/10.1371/journal.pone.0137021.

Jones, K. L.; Rodwell, L.; McCann, K. I.; Verdoorn, G.H.; Ashley, M.V. (2006). Genetic conservation of South African wattled cranes. Biological Conservation 127: $98-106$.

Karanth, K.P. (2003). Evolution of disjunct distributions among wet-zone species of the Indian subcontinent: testing various hypotheses using a phylogenetic approach. Current Science 85(9): 1276-1283.

Keppel, G.; Niel, K.P.V.; Wardell-Johnson, G.W.; Yates, C.J.; Byrne, M.; Mucina, L.; Schut, A.G.T.; Hopper, S.D.; Franklin, S.E. (2011). Refugia: identifying and understanding safe havens for biodiversity under climate change. Global Ecology and Biogeography 21(4): 393-404. Doi: 10.1111/j.14668238.2011.00686.x. 
Kropf, M.; Comes, H.P.; Kadereit, J.W. (2006). Long-distance dispersal vs vicariance: the origin and genetic diversity of alpine plants in the Spanish Sierra Nevada. New Phytologist 172(1): 169-184. Doi: 10.1111/j.1469-8137.2006.01795.x.

Loyola, R.D.; Lemes, P.; Nabout, J.C.; Trindade-Filho, J.; Sagnori, M.D.; Dobrovolski, R.; Diniz-Filho, J.A. (2013). A straightforward conceptual approach for evaluating spatial conservation priorities under climate change. Biodiversity and Conservation 22(2): 483-495. Doi: https://doi.org/10.1007/s10531-012-0424-x.

Lozano-Jaramillo, M.; Rico-Guevara, A.; Cadena, C.D. (2014). Genetic differentiation, niche divergence, and the origin and maintenance of the disjunct distribution in the b blossom crown Anthocephala floriceps (Trochilidae). PLoS ONE 9(9): e108345. Doi: 10.1371/journal.pone.0108345.

Marchant, S.; Moran, A.L.; Marko, P.B. (2015). Out-of-the tropics or trans-tropical dispersal? The origins of the disjunct distribution of the gooseneck barnacle Pollicipes elegans. Frontiers in Zoology 12: 39. DOI 10.1186/s12983-015-0131Z.

Mark, B.G.; Osmaston. H.A. (2008). Quaternary glaciation in Africa: key chronologies and climatic implications. Journal of Quaternary Science 23(6-7): 589-608. Doi: 10.1002/jqs. 1222.

McCann, K.I.; Benn, G.A. (2006). Land use patterns within wattled crane (Bugeranus carunculatus) ranges in an agricultural landscape in KwaZulu-Natal, South Africa. Ostrich 77 (3\&4): 186-194.

Measey, G.J.; Tolley, K.A. (2011). Investigating the cause of the disjunct distribution of Amietophrynus pantherinus, the endangered South African western leopard toad. Conservation Genetics 12:61-70. Doi: 10.1007/s10592-009-9989-7. 
Meine, C.; Archibald, G. (1996). The cranes: status survey and conservation action plan. IUCN, Gland, Switzerland.

Miller, C.S.; Gosling, W.D. (2014). Quaternary forest associations in lowland tropical West Africa. Quaternary Science Reviews 84: 7-25. Doi: http://dx.doi.org/10.1016/j.quascirev.2013.10.027.

Morrison, K.L. and Bothma, J.D. (1998). Wetland nesting sites of wattled and grey crowned cranes on the Steenkampsberg Plateau, South Africa. South African Journal of Wildlife Research 28(4): 110-120.

Osmaston, H.A.; Harrison, S.P. (2005). The late Quaternary glaciation of Africa: a regional synthesis. Quaternary International 138-139: 32-54. Doi: 10.1016/j.quaint.2005.02.005.

Pena, J.C.C.; Kamino, L.H.Y.; Rodrigues, M.; Mariano-Neto, E.; Siqueira, M.F. (2014). Assessing the conservation status of species with limited available data and disjunct distribution. Biological Conservation 170: 130-136. Doi: https://doi.org/10.1016/i.biocon.2013.12.015.

Peterson, A.T.; Soberón, J.; Pearson, R.G.; Anderson, R.P.; Martínez-Meyer, E.; Nakamura, M.; Araújo, M.B. (2011). Ecological niches and geographic distributions. Princeton: Princeton University Press.

R Core Team (2017). R: A language and environment for statistical computing. Vienna, Austria: R Foundation for Statistical Computing. URL http://www.Rproject.org/.

Reside, E.A.; VanDerWal, J.; Kutt, A.S. (2012). Projected changes in distributions of Australian tropical savannah birds under climate change using three dispersal scenarios. Ecology and Evolution 2(4): 705-718. 
Ribeiro, V.; Werneck, F.P.; Machado, R.B. (2016). Distribution dynamics of South American savanna birds in response to Quaternary climate change. Austral Ecology 41: 768-777.

Roberts, E.M.; Stevens, N.J.; O’Connro, P.M.; Dirks, P.H.G.M.; Gootfried, M.D.; Clyde, W.C.; Armstrong, R.A.; Kemp, A.I.S.; Hemming, S. (2012). Initiation of the western branch of the East African Rift coeval with the eastern branch. Natural Geosciences 5: 289-294.

Rubinoff, D.; Jose, M.S.; Johnson, P.; Wells, R.; Osborne, K.; Le Roux, J.J. (2015). Ghosts of glaciers and the disjunct distribution of a threatened California moth (Euproserpinus euterpe). Biological Conservation 184: 278-289. Doi: https://doi.org/10.1016/j.biocon.2015.01.023.

Sandel, B.; Arge, L.; Dalsgaard, B.; Davies, R.G.; Gaston, K.J.; Sutherland, W.J.; Svenning, J.-C. (2011). The influence of late quaternary climate-change velocity on species endemism. Science 334: 660-664.

Schoener, T. W. (1968). The Anolis lizards of Bimini: resource partitioning in a complex fauna. Ecology 49: 704-726.

Schultheiß, R.; Bocnlaer, B.; Riedel, F.; Rintelen, T.; Albrecht, C. (2014). Disjunct distributions of freshwater snails testify to a central role of the Congo system in shaping biogeographical patterns in Africa. BMC Evolutionary Biology 14:42. http://www.biomedcentral.com/1471-2148/14/42.

Sobral-Souza, T.; Francini, R.B.; Lima-Riberio, M.S. (2015). Species extinction risk might increase out of reserves: allowances for conservation of threatened butterfly Actinote quadra (Lepidoptera: Nymphalidae) under global warming. Natureza \& Conservação 12: 159-165. Doi: http://dx.doi.org/10.1016/j.ncon.2015.11.009. 
Thesing, B.D.; Noyes, R.D.; Starkey, D.E.; Shepard, D.B. (2016). Pleistocene climatic fluctuations explain the disjunct distribution and complex phylogeographic structure of the Southern Red-backed Salamander, Plethodon serratus. Evolutionary Ecology 30: 89-104. Doi: 10.1007/s10682-015-9794-3.

Thuiller, W.; Georges, D.; Engler, R.; Breiner, F. (2016). biomod2: ensemble platform for species distribution modeling. R package version 3.3-7. https://CRAN.Rproject.org/package=biomod2

Tinker, J.; Lowe, J.; Holt, J. Pardaens, A.; Wiltshire, A. (2015). Validation of an ensemble modelling system for climate projections for the northwest European shelf seas. Progress in Oceanography 138(A): 211-237. Doi: https://doi.org/10.1016/j.pocean.2015.07.002.

Vitorino, L.C.; Lima-Ribeiro, M.S.; Terribile, L.C.; Collevatti, R.G. (2016). Demographical history and palaeodistribution modelling show range shift towards Amazon Basin for a Neotropical tree species in the LGM. BMC Evolutionary Biology 16: 213. Doi: 10.1186/s12862-016-0779-9.

Warren, D.L.; Glor, R.E.; Turelli, M. (2008). Environmental niche equivalency versus conservatism: quantitative approaches to niche evolution. Evolution 62: 28682883. Doi: 10.1111/j.1558-5646.2008.00482.x.

Wethey, D.S.; Woodin, S.A.; Berke, S.K.; Dubois, S.F. (2016). Climate hindcasts: exploring the disjunct distribution of Diopatra biscayensis. Invertebrate Biology 135(4): 345-356. Doi: 10.1111/ivb.12147. 
List of tables

Table 1. Patterns of range shifts and niche overlap between timescales. Columns 3-5 represent the number of cells predicted as gained $(G)$ or lost $(L)$ across two time slices and the corresponding balance (GL). Columns 6-7 represent measures of niche similarity and dissimilarity (Schoener's $D$ and Warren's $I$ ) across time scales.

\begin{tabular}{lllllll}
\hline From & To & G & L & GL & $D$ & $I$ \\
\hline$\sim 130$ kya & $\sim 22$ kya & 146,449 & 30,753 & 115,896 & 0.255 & 0.398 \\
$\sim$ 22kya & $\sim$ 6kya & 17,430 & 63,143 & $-45,713$ & 0.679 & 0.775 \\
$\sim$ 6kya & 0k & 9590 & 21,073 & $-11,483$ & 0.860 & 0.895 \\
\hline
\end{tabular}

Table S1. Bugeranus carunculatus presence records at the Global Biodiversity Information Facility.

Table S2. Models performance

Table S3. Differences (paired $t$-test) of climatic suitability across timescales 
Figure captions

Fig1. The extent of occurrence (EOO) of the wattled crane in Africa and the occurrence records $(n=232)$ used for distribution modelling, obtained after data cleaning and filtering. Note that the number of occurrence records available at the GBIF database (Table S1) is much larger that the number displayed here. For colours, the reader is referred to the web version of the paper.

Fig2. Predicted suitability for the wattled crane, Bugeranus carunculatus, across the Afrotropical realm. A) Last Interglacial ( 130 kya); B) Last Glacial Maximum ( 21kya); C) Mid-Holocene ( 6ka); D) Current climate (0kya). Warmer colours correspond to areas with higher probability of occurrence. Black line represents the borders of the Afrotropical realm (Olson et al. 2001) and dashed lines represent the IUCN EOO (IUCN, 2017). For colours, the reader is referred to the web version of the paper.

Fig3. Patterns of climatic range shifts for the wattled cranes in the Afrotropical realm through time. A) Range shifts between the LIG and LGM; B) Range shifts between the LGM and Mid-H; C) Range shifts between the Mid-H and present climate scenarios; D) Overlap of climate suitability across all time slices. In A-C, red indicate areas that lost suitability and green indicates areas that gained suitability. In D) areas in red represent potential climatic refugia for the species, or areas that have maintained highly suitable through all timescales. For colours, the reader is referred to the web version of the paper. 
FigS1. Predicted a) Last Interglacial ( 130 kya), b) Last Glacial Maximum ( 21 kya),

c) Mid-Holocene ( 6 kya) and d) current (0 kya) distribution of the wattled crane.

Superimposed is the IUCN extent of occurrence (EOO). 


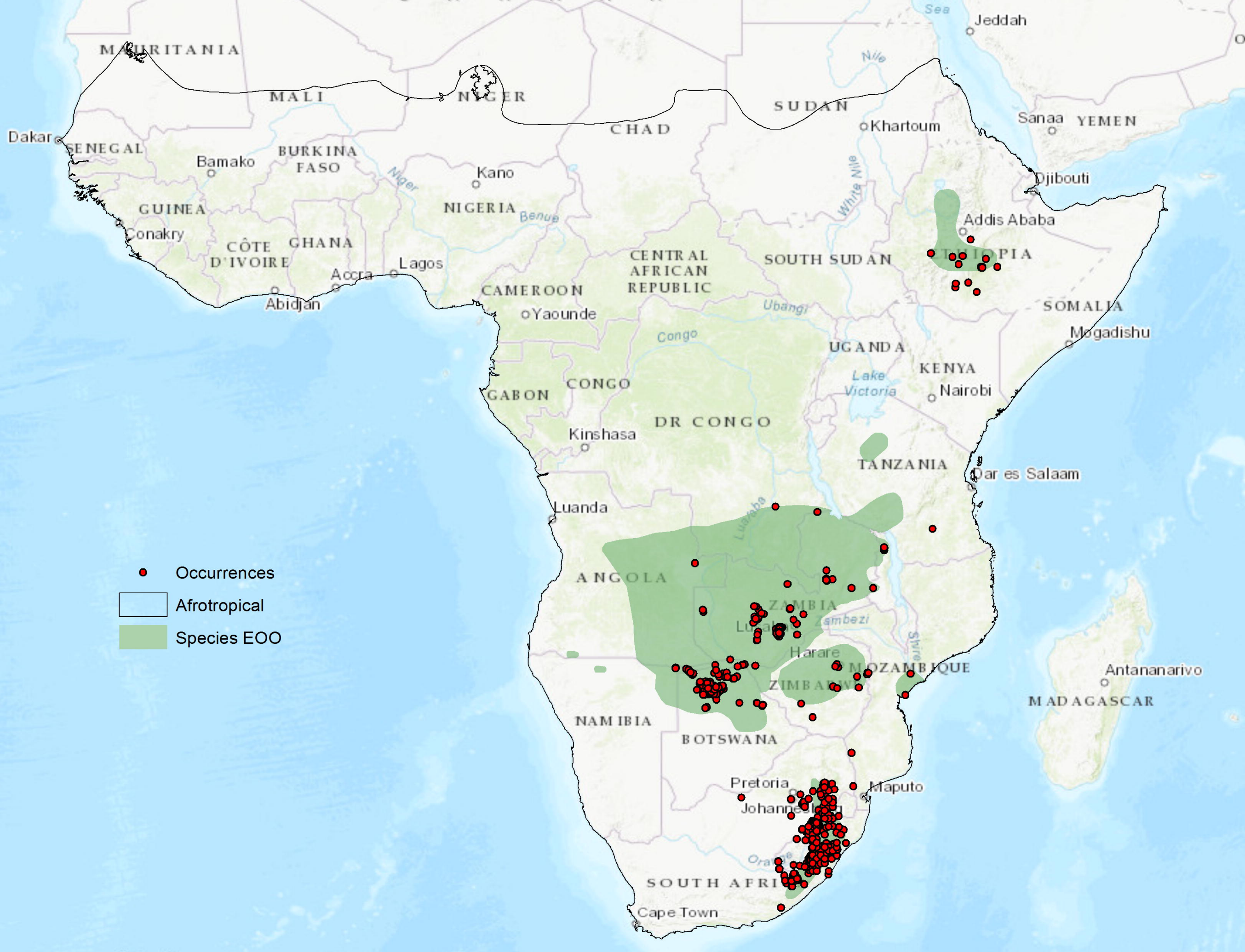


$(a)$

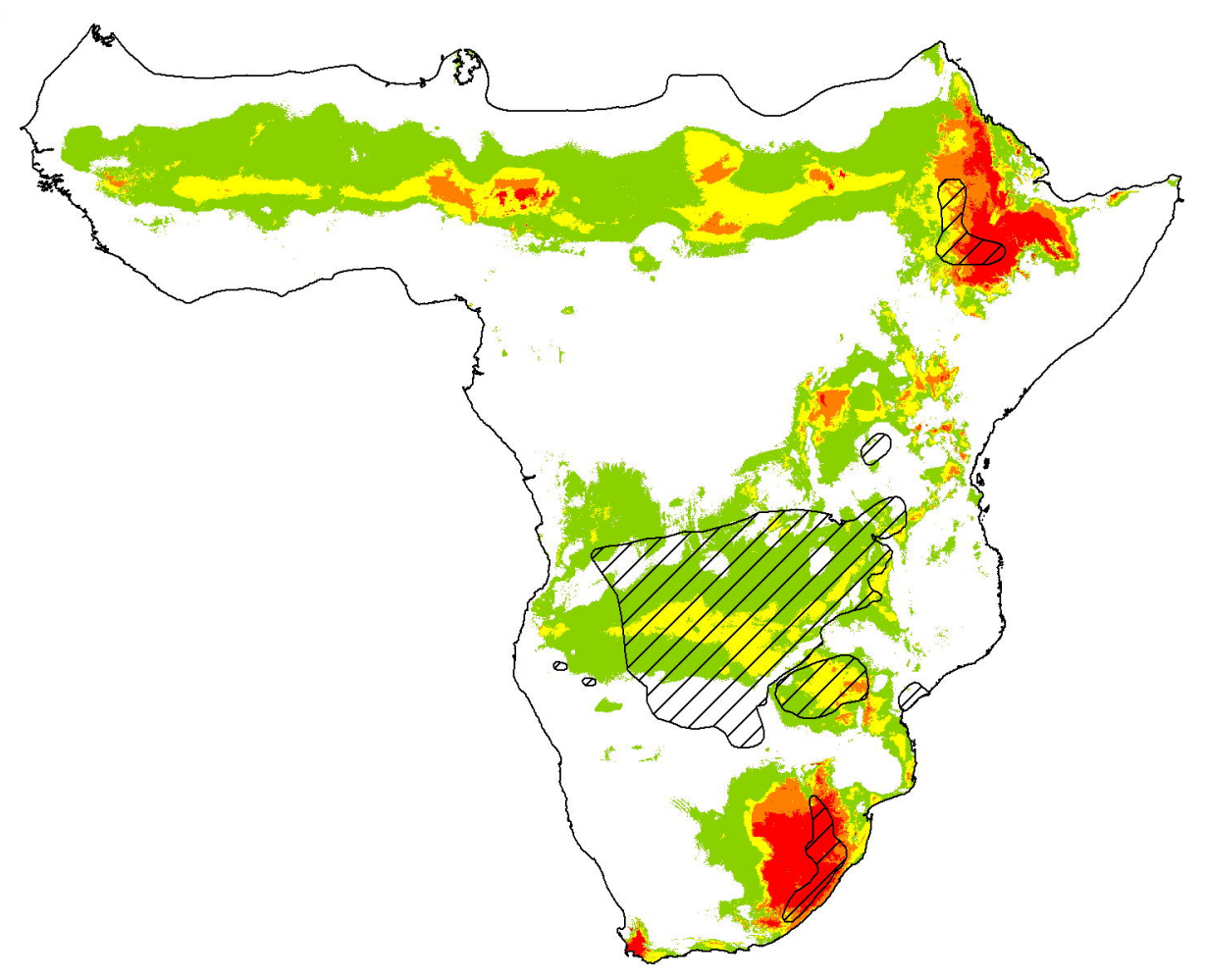

(c)

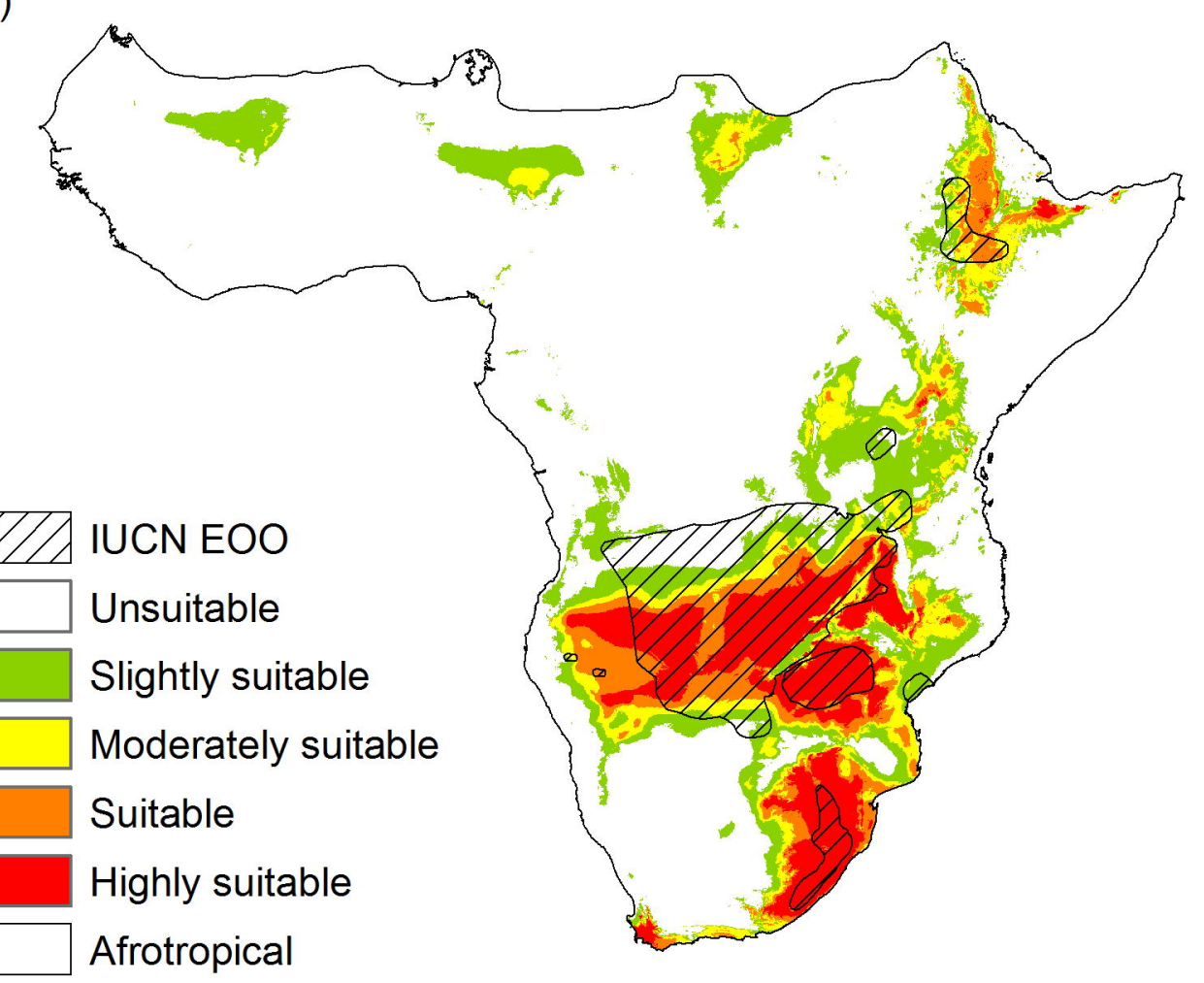

(b)

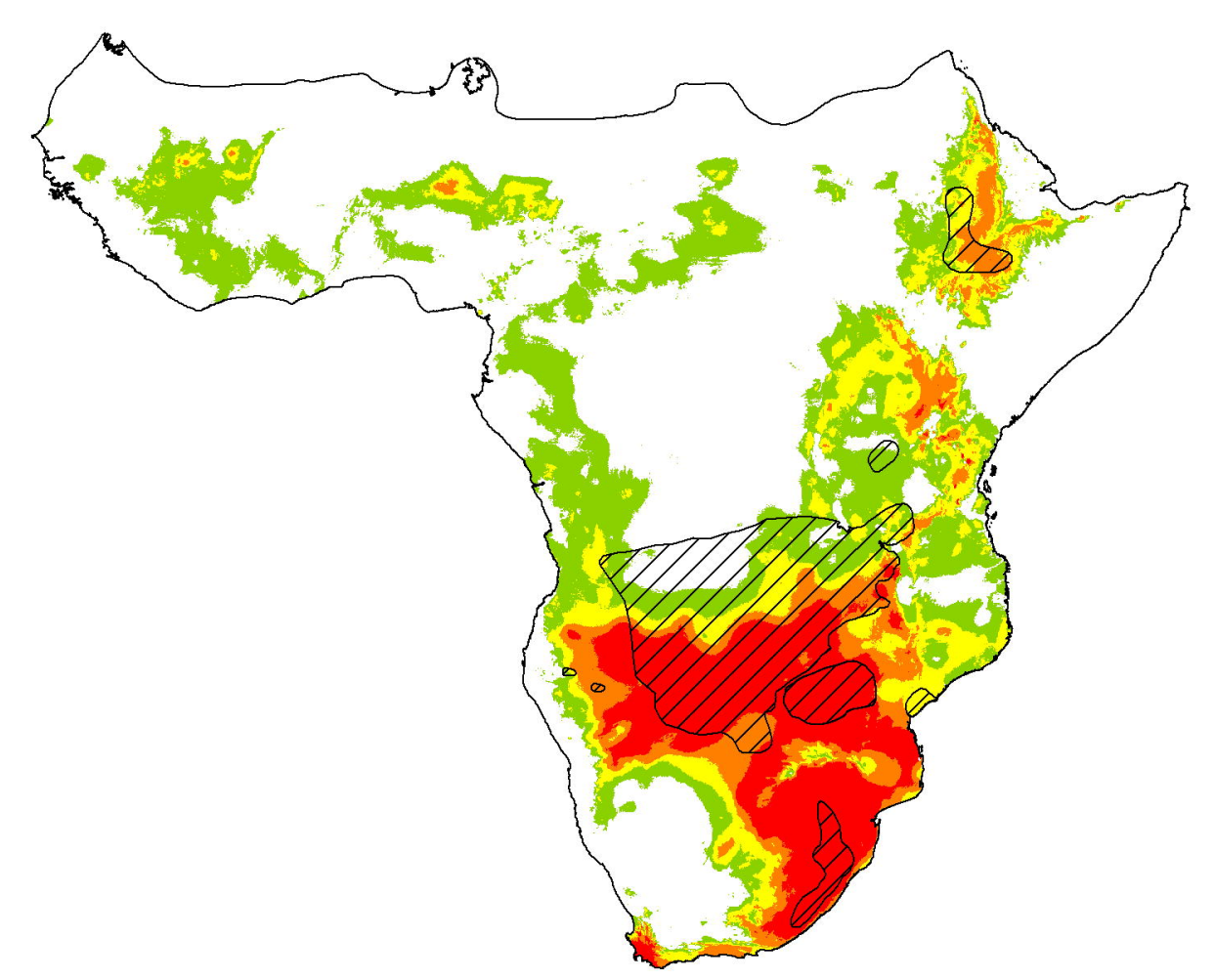

(d)

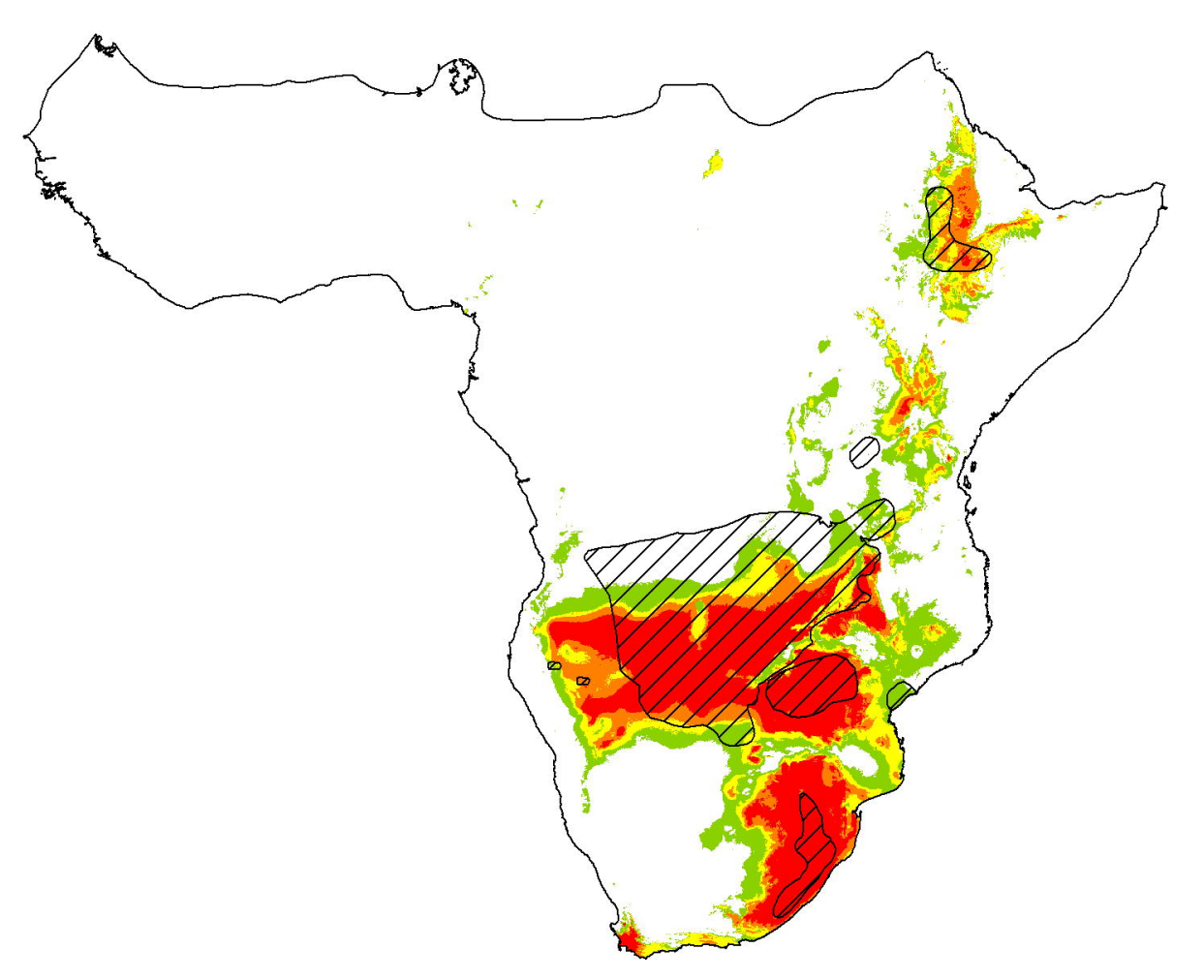


(a)

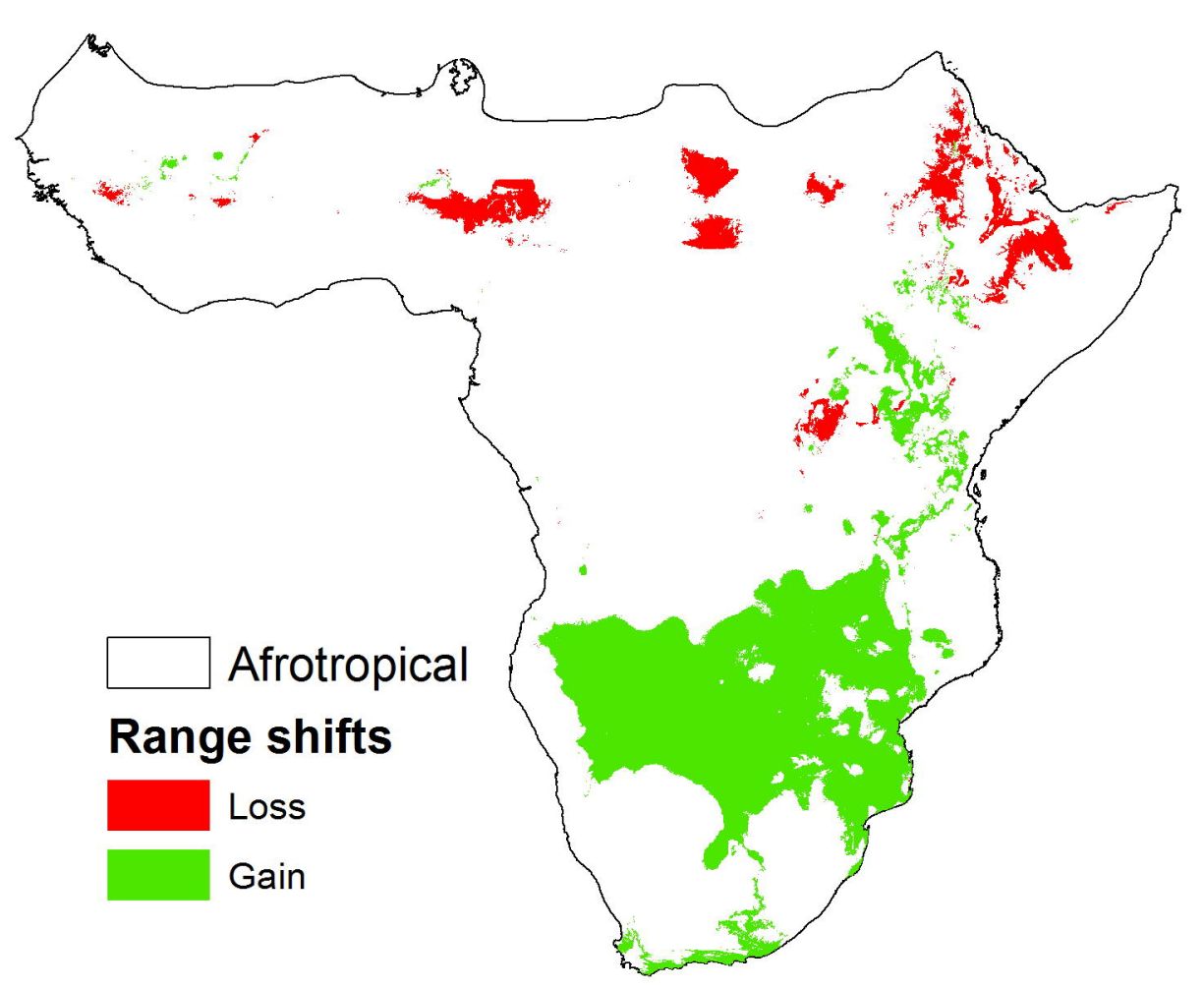

(c)

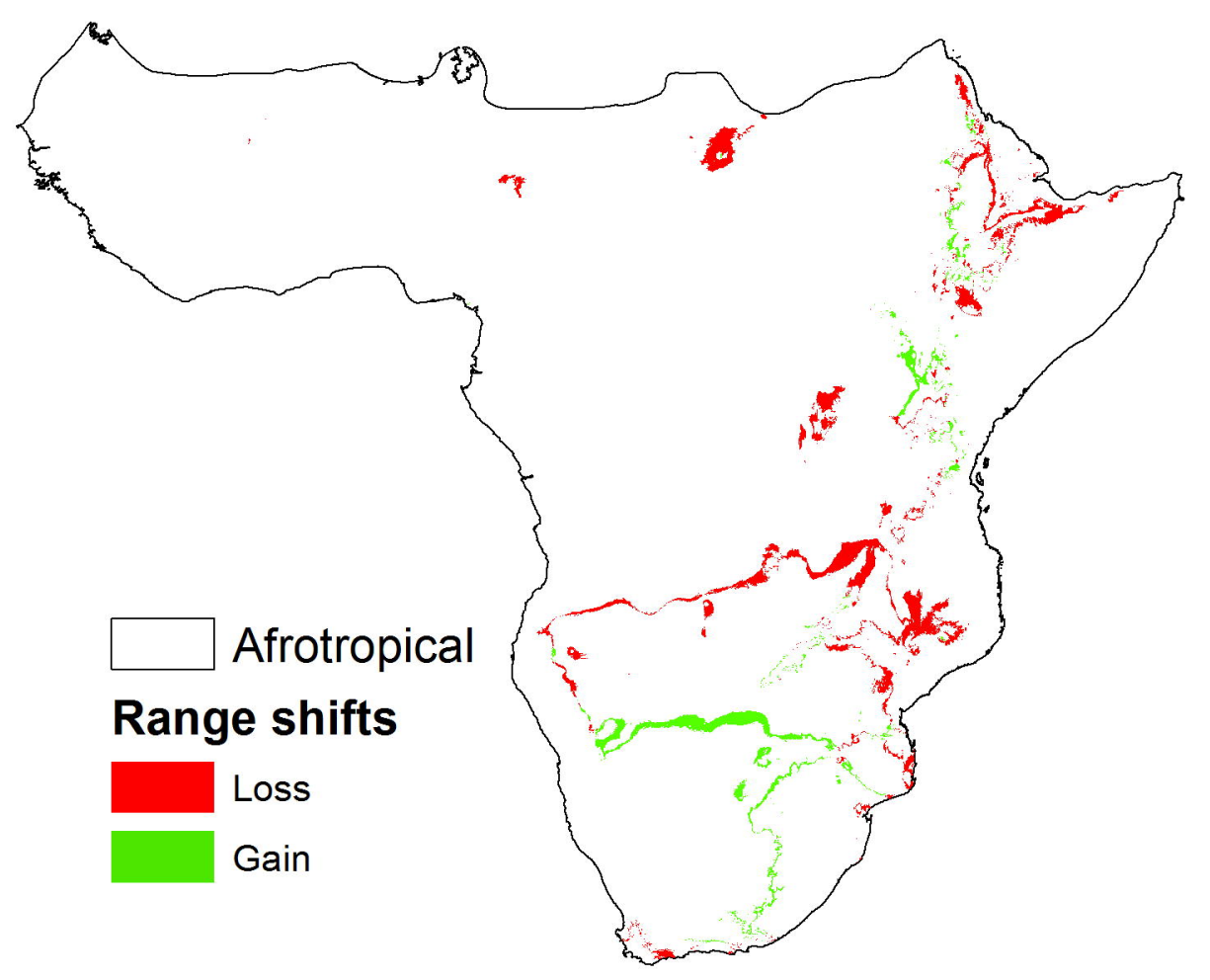

(b)

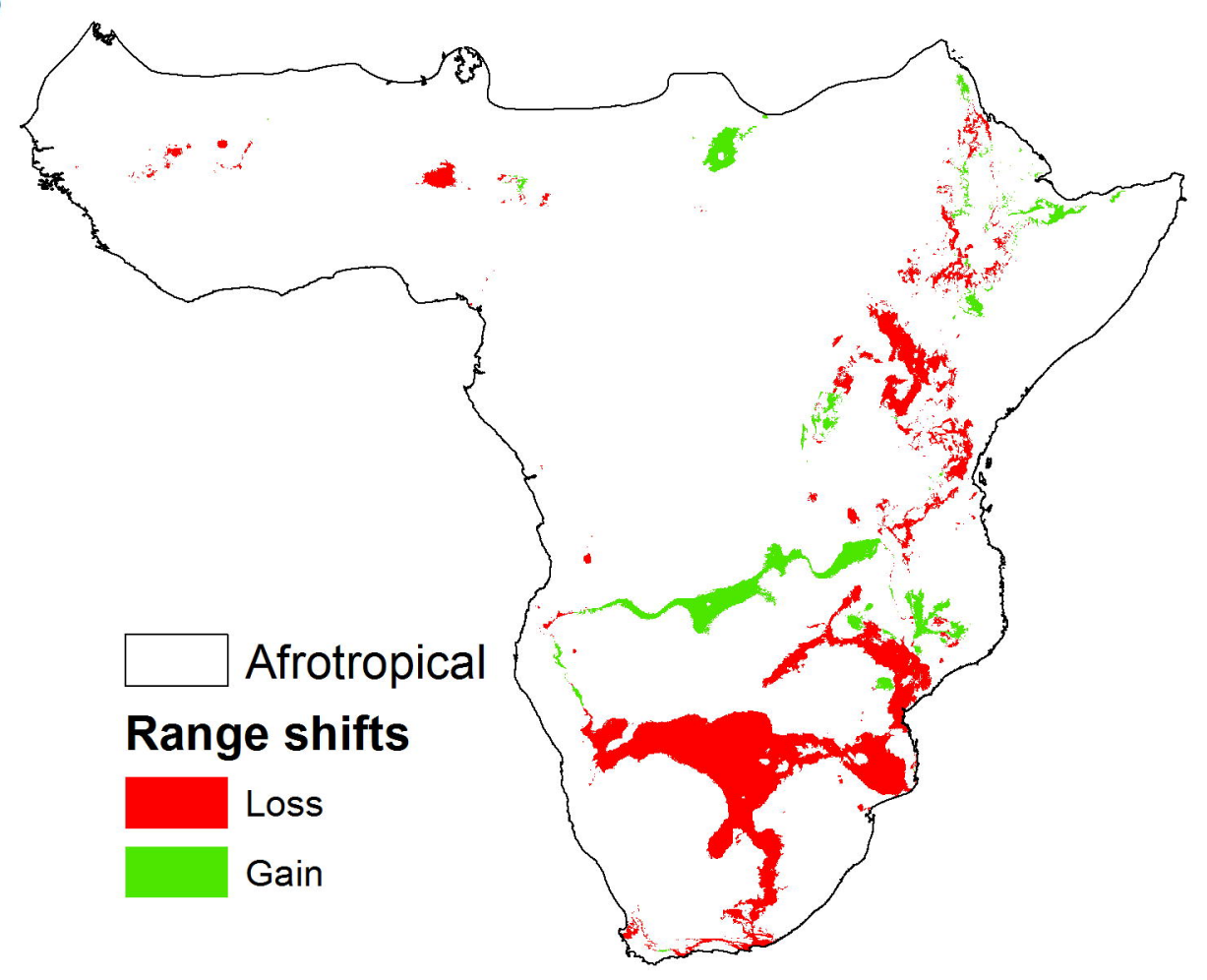

(d)

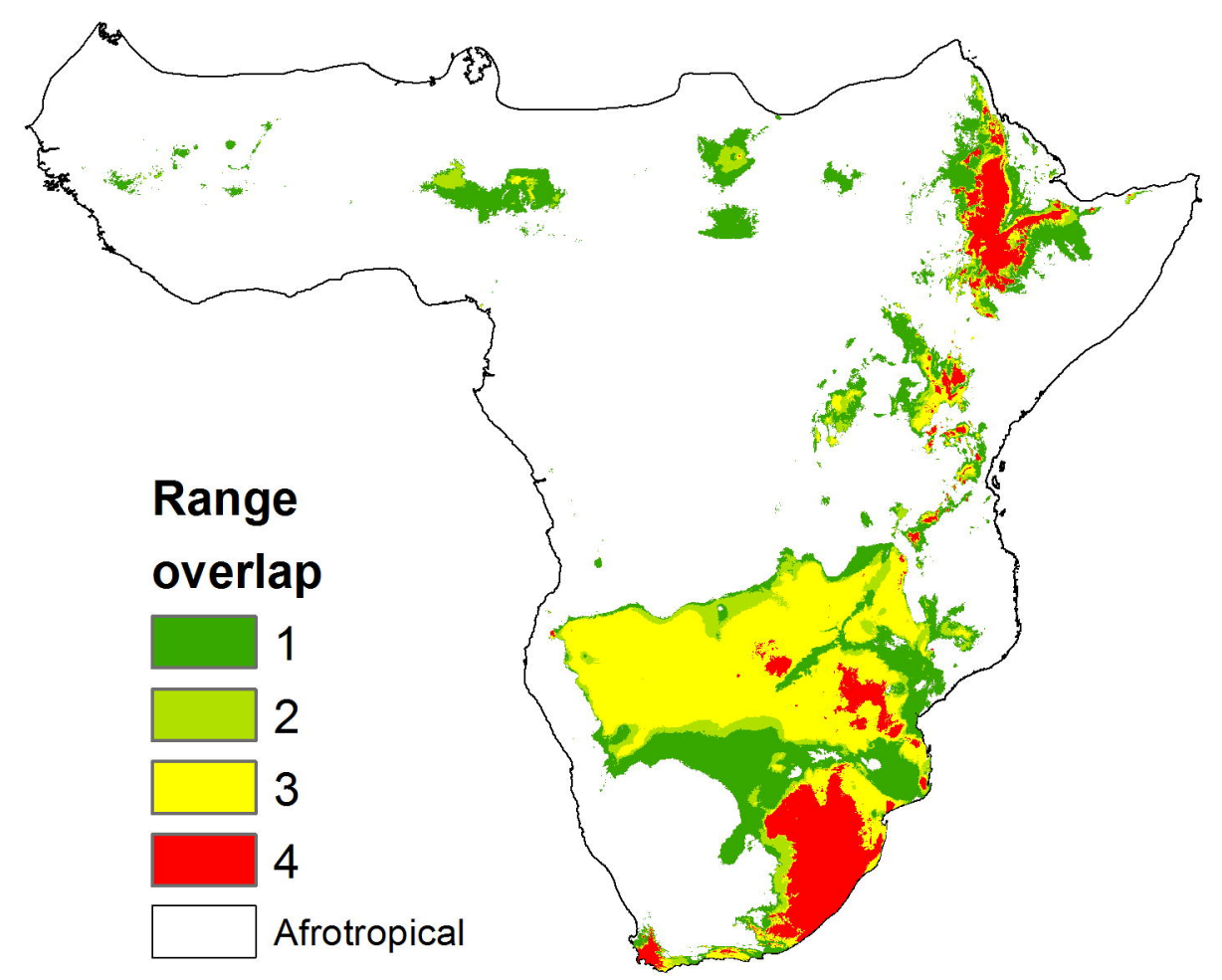

